\title{
ENTRE EL BON ICE Y LA ESTETICA DEL AMAGUE Guia de bolsillo para iniciar un proceso de interrelación arte y comunidad
}

\author{
Pablo Almeida Egas
}

Fecha de recepción: 04/2016

Fecha de aceptación: 11/2016

\begin{abstract}
Resumen:
Indicaciones generales y guía primordial al inicio del desarrollo de propuestas en el territorio sobre arte y comunidad, puntos a tomar en cuenta, ejemplos y casos específicos, espacios de negociación entre algunas posibilidades; la Mediación, el Proceso y la Presentación Final.
\end{abstract}

Palabras claves: : Comunidad, vecinos, interrelación, honestidad.

\begin{abstract}
:
This article provides information and constitutes a guide for development of art and community project proposal as well as examples and negotiation study cases.
\end{abstract}

Keywords: community, neighbors, interrelation, honesty.

\section{Autor:}

Pablo X. Almeida Egas (Quito-Ecuador, 1973). Artista visual, productor y gestor contracultural. Licenciado en arte por la Facultad de Artes de la Universidad Central del Ecuador (2003). Miembro fundador del Colectivo de arte Tranvía Cero (2005-2015), investigador y productor general del Encuentro de arte y comunidad al zur-ich (2003-2016). Ha participado junto al colectivo Tranvía Cero en seminarios, proyectos internacionales y bienales como Espacios Culturales Urbanos, Sao Paulo-Brasil (2015), La Otra Bienal de Arte, Bogotá-Colombia (2013), Museo+Territorio, Museo de Antioquia, Comuna 1, Medellín-Colombia (2013), XI Bienal de la Habana-Cuba (2012), Premio Salón Nacional de las Artes Mariano Aguilera, sección Proyectos, Quito (2012-2013), Proyecto Internacional MDE 11, Medellín-Colombia (2011), Zonadearteenacción, Buenos Aires-Quilmes-Argentina (2010), X Bienal Internacional de Cuenca-Ecuador (2009), Semana Cultural en España, espacios postfronterizos, Casa de América, Madrid-España (2009), interesado en propuestas que aborden la Condición Humana, la estética underground y el ser alterado. 


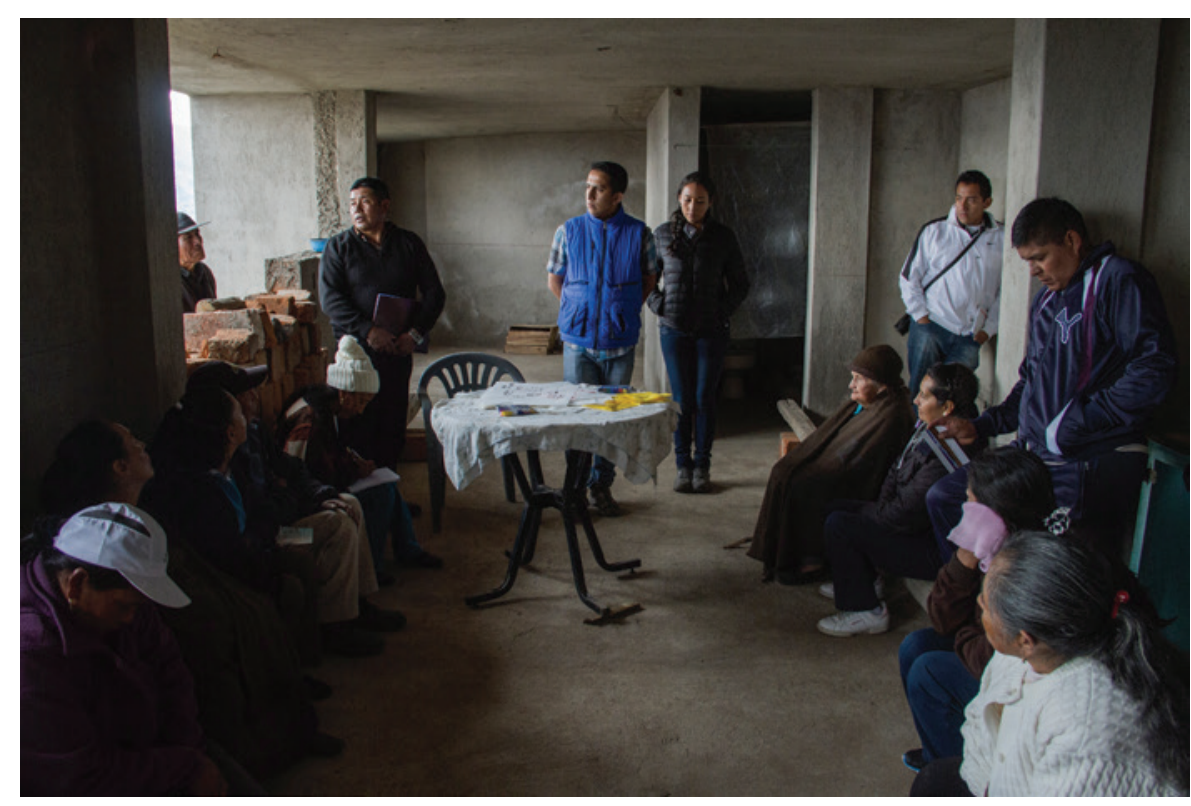

Fig. 1, Foto del proyecto Revita 1, propuesto por el Colectivo de arquitectos C3, a intervenir en el sector de Bellavista del Sur, en el marco del XIII Encuentro de arte y comunidad al zur-ich 2015, foto propiedad de la memoria $\mathrm{Al}$ zur-ich.

"El otro día quise conocer verdaderamente la identidad de este pueblo, pero me cabrea caminar tanto por La Marín ${ }^{1}$

\section{Introducción}

Las diversas formas de incidir en el territorio y que inician los procesos socioculturales comunitarios nunca han sido fáciles, más bien están cargados de mucha complejidad, tensiones, intereses, terquedades y dosis muy fuertes de alteridad; hay conceptos e ideas claras que se deben manejar al hablar de arte y comunidad, por ejemplo: nadie está dando haciendo las cosas ni dando pensando; las personas y comunidades se merecen el mismo respeto y consideración que los colaboradores, luego si estás intentando utilizar para tus propios intereses

1 Cita creada por el autor, alude al sector de la Marín en Quito, sitio muy popular y de gran confluencia vehicular, con paradas de bus, ventas ambulantes, comercios, rateros, mucha bulla y de una gran riqueza socio-cultural, revisar https://www.youtube.com/watch?v=NfJHXzcrCoQ o alter ego a los diversos grupos sociales es mejor que no lo hagas y lo pienses bien ya todo grupo humano tiene sus propios procesos culturales, su propia riqueza antropológica y lo óptimo es llegar, aprender, enseñar y volver a aprehender, una simbiosis, intercambiar los saberes y apoyar las inquietudes, nadie va a culturizar a nadie, partiendo desde esa horizontalidad se puede empezar a trabajar in situ.

A lo largo de este texto autoral sobre la gestión y producción cultural voy a referirme en cierta medida a la forma de accionar del colectivo de arte quiteño Tranvía Cero (Ayala, Cortez, Almeida) y a ciertos proyectos gerenciados por el Encuentro de arte y comunidad al zur-ich (Tituaña, Villarroel, Almeida).

Bajo estas puntualizaciones se tratará de establecer algunas normativas en el discurso del trabajo arte-comunidad, estableciendo ciertos temas transversales: Mediación, Proceso y Presentación Final. 


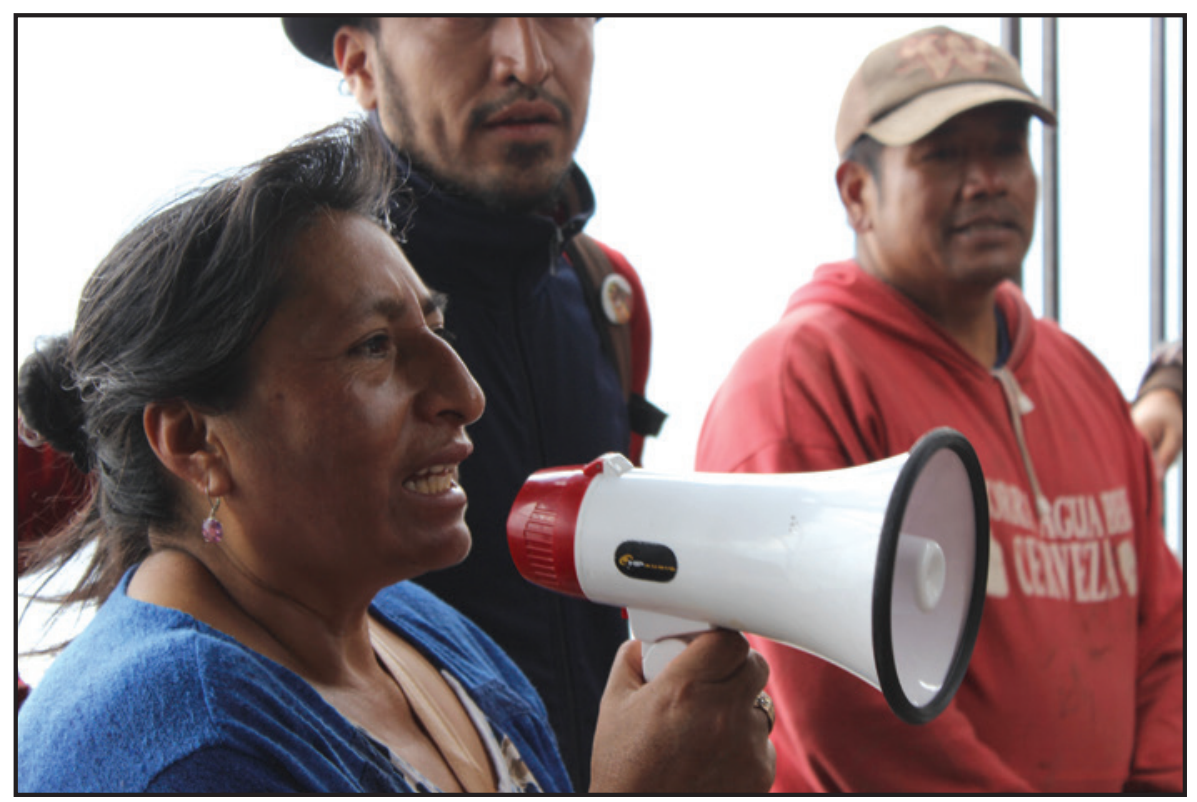

Fig. 2.- Foto del proyecto Reflejo Común, propuesto por el artista José Luis Macas, acción pensada en el camino del Qhapac Nan, sector de La Forestal, la señora Luz Tenemea, aguerrida dirigente barrial, aporta en el diálogo y ese nexo con los habitantes, en el marco del XIII

Encuentro de arte y comunidad al zur-ich 2015, foto propiedad de la memoria $\mathrm{Al}$ zur-ich

\section{Mediación (primer paso)}

Concepto técnico contemporáneo que se lo utiliza en muchos casos para resolver algunas oraciones institucionales; hace quince años era encontrar toda una riqueza humana en los sectores donde se intervenía, sin querer ser santurrón pero esta Mediación era especialísima al momento de interactuar.

Vinculación (como se la conocía) consiste en el acercamiento, en el buenos días buenas tardes, no sea malita, es verdaderamente enfrentarse al habitante, comunicar las problemáticas, discutir las necesidades y proponer soluciones y visibilidades desde el campo socio-cultural (que muchas veces no significa mucho pero visto desde lo macro, genera un proceso importante de extrañamiento y alteridad), por ahí el método de vincularse es importante en el análisis del territorio y la correcta abstracción de la problemática, en este desarrollo tan cuestionado de los proyectos culturales y especialmente de la gestión cultural.

Ahora, la participación barrial es una parte muy importante de la actividad comunitaria, el interés debe estar enmarcado en esas necesidades colectivas y tener claro los objetivos, no siempre la masiva participación es un termómetro del éxito como tampoco la escasa concurrencia asume el fracaso del mismo, el leitmotiv son los lineamientos claros y objetivos a cumplirse (especialmente los específicos), eso determina la salvedad y notoriedad del proyecto ejecutado.

Para ir comentando este duro proceso que significa mediar la participación, tomaré un par de ejemplos Revita 1 (Fig. 1), los autores, un colectivo joven de arquitectos quiteños C3, concretan una serie de reuniones y un cronograma específico para ir determinando el cuerpo del proyecto; su idea básica es la 
construcción de una casa comunal que sirva para las diversas actividades del barrio, a las reuniones explicativas asiste un público totalmente heterogéneo pero interesado en apoyar la idea, sabiendo que en el camino existe una gran cantidad de dificultades, al igual que en Reflejo Común (Fig. 2), el proponente José Luis Macas, explica, junto a la dirigencia barrial especialmente la gran señora Luz Tenemea, su interés de detonar una acción, una caminata por los senderos del Qhapac Nan (camino ancestral) y que es básica la participación colectiva para ir activando esa energía vital que emite el ser humano en estos espacios; estos momentos de la mediación del proyecto son muy importantes desde la utilización de códigos del lenguaje, socios estratégicos y apoyos técnicos que usa el proponente para el entendimiento del mismo (ambos proyectos fueron realizados, gestionados y producidos dentro del marco del XIII Encuentro de arte y comunidad al zur-ich 2015, ver www.arteurbanosur.blogspot.com )

\section{Proceso (segundo paso)}

Cabe insistir en que al hablar de cultura pretendemos tener en cuenta una realidad que rebasa la consideración de la vida social como un conjunto de funciones entre las que estaría la función específicamente cultural. Nos referimos a una dimensión del conjunto de todas ellas, a una dimensión de la existencia social, con todos sus aspectos y funciones, que aparece cuando se observa la sociedad tal como es cuando se empeña en llevar a cabo su vida persiguiendo un conjunto de metas colectivas que la identifican o individualizan (Echeverría, 2010). ${ }^{2}$

¡Vea vecina, cómo le va! Estamos haciendo un proyecto de arte que le va a permitir identificarse como comunidad, hay unos artistas interesados en trabajar en este sector

2 Bolívar Echeverría, Definición de la Cultura (México: ITACA 2010) 39-40. debido a sus referencias históricas y............

Quésfff eso?

Un proyecto cultural, hay danzas, charlas y aportes teóricos.

No no, gracias. Vaya vaya no más...

No sea así, vea, venga y le cuento, llame a sus hijos y amigas.

Bueno pero un ratito no más que estoy apurada, ahura que no llegue el bus.

(María Chicaiza, vecina de la tienda de Chillogallo)

Generalmente las reflexiones al entrar al sitio de conflicto tienen varios matices y varias particularidades, la comunidad maneja sus tiempos y agendas, uno como sujeto es el intruso y eso se debe dejar por sentado siempre. Los espacios de diálogo se crean bajo nuestras necesidades, pero los contenidos deben ser desarrollados por los interesados dentro del ámbito, la discusión más importante se la va desarrollando a través de las asambleas y reuniones barriales hasta llegar a ciertas concesiones, luego lo importante y debatible es establecer parámetros de discusión y evaluación de lo ocurrido.

Siguiendo con este tipo de estrategias y luego de ejecutar las herramientas pedagógicas comunes, la intención de los proponentes tiene que ser lo menos invasiva y represiva posible ya que todo tipo de tácticas in situ tienen formas represivas sistemáticas y lo cultural no queda descartado dentro de la lista: educación, religión, política; ahora el hecho reflexivo afronta una serie de dificultades que deben ser solventadas en el camino, de ahí la importancia del taller (pictórico, teórico, escénico, audiovisual) como método infalible para desamarrar nudos, pero este no como fin último del proceso, siempre se debe proponer generar productos que se salgan 
del ámbito netamente pedagógico-impositivo, interesa más buscar el meollo del proyecto, el por qué estamos trabajando en tal o cual comunidad, situación o propuesta, luego se llega a un acuerdo generalmente en asamblea (proponentes-comunidad-socios estratégicos), para determinar el medio visual de presentación.

Algo muy importante en esta etapa es nunca perder el contacto con las personas y participantes objetivos, de esto depende muchas veces el éxito o fracaso del proyecto. Este sistema no es infalible, tiene muchas fallas pero nos ha servido como sistema de trabajo al abordar las estrategias interrelacionales dentro del colectivo de arte Tranvía Cero, produciendo proyectos in situ tanto en el país como en algunas parte de América Latina, todo el background y el camino recorrido se ha ido asfaltando también con muchas equivocaciones y desaciertos, pero que han corroborado siempre esa necesidad de proponer métodos comunicacionales, más allá de la media básica, buscar otras formas de relacionamientos y especialmente movilizar desde la frontalidad y claridad del proyecto. ${ }^{3}$

3 El autor hace referencia al trabajo sostenido del Colectivo de arte contemporáneo Tranvía Cero (2005-2015).

"Nosotros no trabajamos para la comunidad ni por la comunidad, nosotros trabajamos con la comunidad".

Entendemos que la producción y circulación de los bienes culturales no están determinados por museos, galerías ni sitios de concentración elitista, la relación se la consigue con el diálogo y el cuestionamiento dentro del barrio, en la comunidad donde se crean espacios de discusión, así trabajamos en procesos colaborativos y de construcción participativa. (...) El trabajo en colectivo nos ha despertado una serie de intereses y acciones comunes, una de ellas es el inmiscuirnos en el espacio público, luego pensar en la idea de democratizar las prácticas artísticas y de experimentar con lenguajes distintos dentro de las artes visuales; todo esto ha dado paso hacia una búsqueda de alternativas de producción que están más ancladas a una nueva realidad y nuevas formas de relacionarse.

$\mathrm{Si}$ bien es cierto Tranvía Cero se convirtió en un referente de procesos relacionales y ha influenciado el accionar de diversos colectivos, creemos que nuestra
Cuando se habla de arte contemporáneo dentro de las asambleas o reuniones se corre muchas veces el peligro de ahuyentar a la masa crítica más importante dentro del proyecto que son los vecinos y las personas del barrio, ya que muchas veces se llega con tecnicismos neocolonialistas, falsas expectativas, metalenguajes que no vienen al caso, preferimos nombrarlos como experiencias, aprendizajes o actividades en el sector, de ahí que nuestra presencia como autores, artistas, promotores se va difuminando en el camino, la autoría ya no es nuestra (esta solo sirve para los informes o los currículos), los dueños de lo obra es la comunidad que participó con su tiempo, con sus ideas, con sus formas de comunicarse y con su interés de incidir en el modus vivendi comunitario.

Esta idea de proceso la voy a explicar en la propuesta Mafalda Vive (Fig.3 y 4) fue un proyecto en colaboración con algunos colectivos de diseñadores, artistas, activistas, gente de la comunidad, organizaciones de base de Ecuador y España, entre ellos: MAKEA tu vida, Tranvía Cero, Embajada de España, Fundación Paulo Freire, el vecino del salón para almorzar, la doña de la ferretería y las monjitas

incidencia más grande está en la discusión de procesos comunitarios, propiciando espacios de diálogo, de discusión, intercambio creativo y además detonando procesos políticos como formas de transformación social y resistencia. Hemos tratado de entender y re-significar al espacio público como una fabulación del poder que divide lo privado de lo común, división que en la práctica solo sirve para articular una ciudad sectorizada, que limita la intervención de sus propios usuarios o actores y descarta todo tipo de apropiación de los espacios comunes. Como plataformas y prácticas hemos trabajado, producido y gestionado el Encuentro de arte y comunidad al zur-ich (2003-2013-luego de esta fecha el Encuentro camina solo), la Documenta Internacional de arte acción Mishqui Public (2008) y El Tanque, Laboratorio de artes nómadas (2012-2015). La alineación actual (2016) del Colectivo Tranvía Cero es: Pablo Ayala, Karina Cortez y Pablo X. Almeida. 


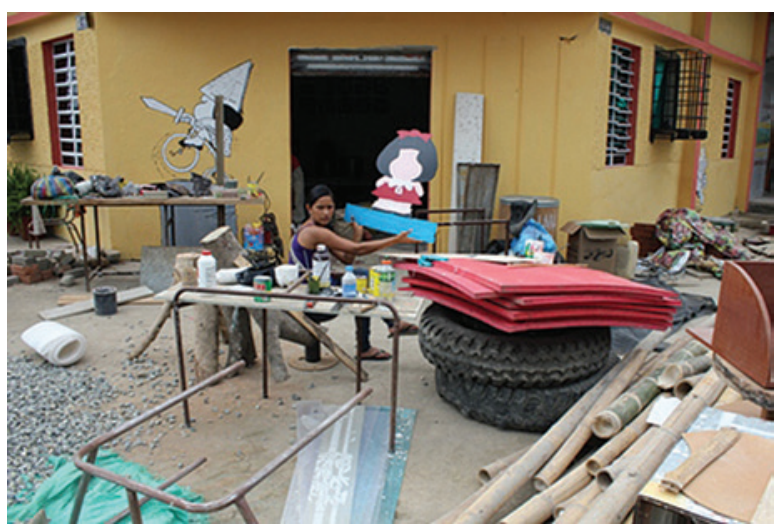

Fig.3. Foto del proyecto Mafalda Vive, construcciones alternativas para la creación de bibliotecas infantiles, desarrollado por el colectivo Tranvía Cero, Makea Tu Vida (Espańa) y varios actores culturales de la región, profesores, estudiantes, arquitectos, gestores culturales, proceso trabajado en la población de Montalvo, provincia de Los Ríos, (2012)

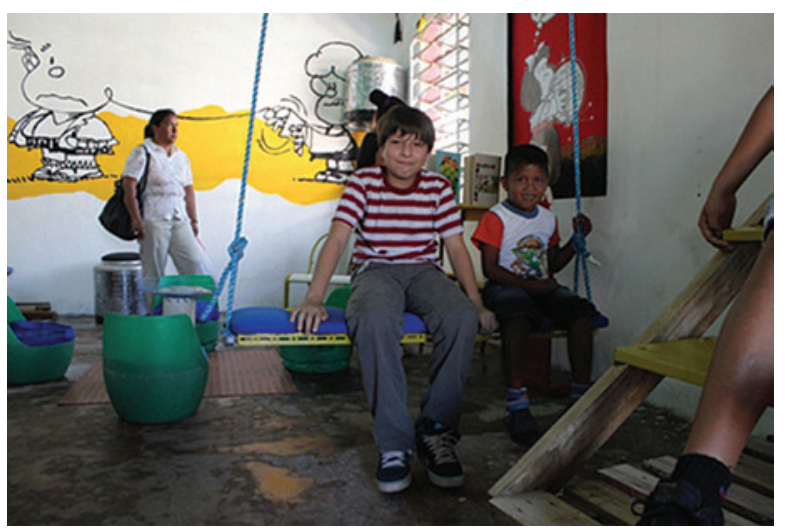

Fig. 4.- Termina el proceso de Mafalda Vive, con la presentación del mobiliario.

donde nos ubicaron para dormir, todo esto para la creación de mobiliarios y espacios dirigidos hacia la lectura, especialmente para niños y jóvenes, gestionados por la gente del lugar (en este caso el cantón Montalvo de la provincia de Los Ríos):

...una palabra muy importante para nosotros en esta labor, es el proceso, ese tiempo de trabajo arduo que está entre la presentación y la despedida, es un espacio de tiempo importante donde se tejen un sinnúmero de redes, alianzas, posturas, gustos, pero siempre se genera una gran amistad que se alimenta día a día por el trabajo, arrimar el hombre para apoyar el proyecto, al final el resultado visible sirve para las redes sociales, el currículum para los que le apostaron al trabajo, a la historia del arte, a la comunidad (por supuesto) y a unas cuantas personas que tarde o temprano sacarán su tajada; pero el resultado que más nos interesa y creemos de mayor importancia es aquel que no parece visible, ese que se forjó en el almuerzo, en la cantina, en el taller, al compartir un par de cervezas o unas piezas de baile, un mal chiste, el último ron o un cigarrillo a medio fumar, esos instantes fugaces son los que duran para siempre y han ido consolidando la base del trabajo ${ }^{7}$. (Las Biblios Creactivas, 2012)

Esta etapa contiene un sinnúmero de problemáticas y complejidades, en La Patrona de la Cantera (gráfico 5) hace referencia a un proceso más íntimo de diálogo, de discusión, Falco (artista cuencano) como proponente plantea crear una imagen icónica que represente a su Patrona, a la trabajadora, a la meretriz y sus procesos son diferentes basados en las experiencias y motivaciones: el taller de dibujo, la caracterización, la teatralidad funcionan muy bien en este espacio muy llevado a la corporeidad, a la sensualidad y lucha gremial.

\section{En Frontera (gráfico 6) de Patricio Dalgo} se manejan otros motivos, los proyectos irruptivos tienen diferentes posiciones, desde las personales hasta las políticas y sus relacionamientos van por el impacto visual, el choque emotivo, la avería inteligente del sistema; este proyecto se lo realiza en Huaquillas-Aguas Verdes, frontera entre Ecuador y Perú, para borrar momentáneamente esta división política y unir estos dos países mediante una manguera de gas para cocinar papas, es decir el tanque de gas estaba en el lado ecuatoriano (gas nacional), luego la manguera y la cocina en el lado peruano, se utilizan papas de los dos países y el ají era netamente peruano, esta cocinada termina con el obsequio y degustación de las personas que transitan por este puente internacional, por ahí 


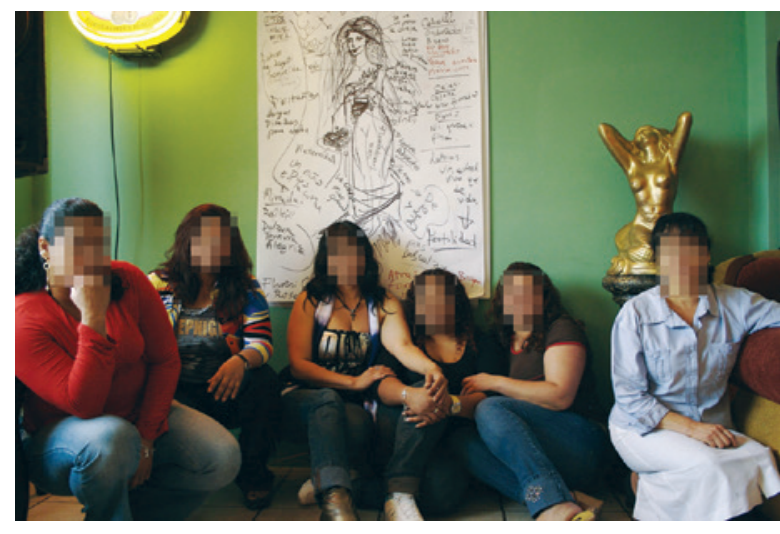

Fig. 5 Foto del proyecto La Patrona de la Cantera, propuesto por el artista cuencano Falco, desarrollar una imagen icónica dentro del cabaret Danubio Azul en el sector de la Cantera, San Roque, Centro de Quito, en el marco del VI Encuentro de arte y comunidad al zur-ich 2008 . Foto propiedad de la memoria al zur-ich

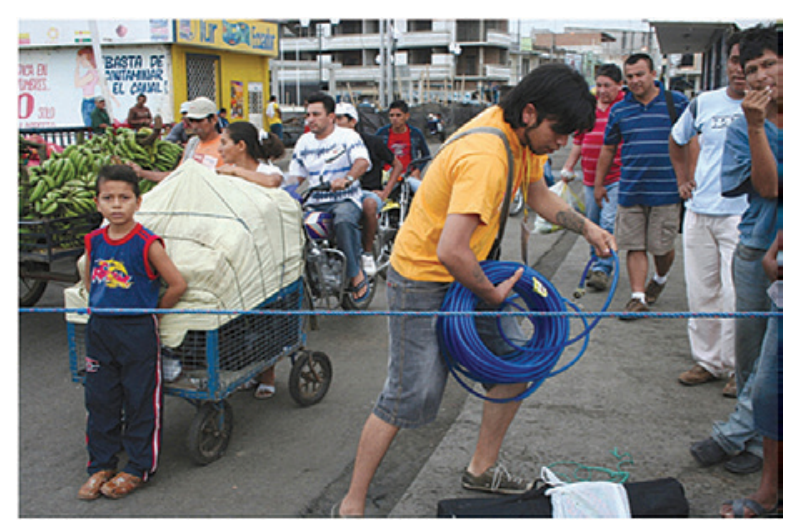

Fig. 6. Foto del proyecto Frontera, realizado por el artista Patricio Dalgo, dentro del marco del VI Encuentro de arte y comunidad al zur-ich 2008, acción en la frontera Huaquillas-Aguas Verdes (Ecuador-Perú), foto propiedad de la memoria al zur-ich

lo que estaba escondido era el tráfico del gas, el mismo que se lo realiza clandestinamente en camiones y carros con todas las problemáticas que esto conlleva. (Tanto el proyecto Patrona de la Cantera y Frontera fueron desarrollados, gestionados y producidos dentro del marco del VI Encuentro de arte y comunidad al zur-ich 2008, revisar www.arteurbanosur.blogspot.com ).

\section{3.-Presentación final (tercer paso)}

Siempre se corre cierto peligro en el instante de la presentación ya que muchos proyectos con estos membretes buscan el aprovecharse de gentes, archivos, memorias y luego no existe una retroalimentación, por eso es importantísimo en los procesos interrelacionales trabajar de una manera sumergente:

...están sumergidos en procesos
reticulares de sus encuentros y
organizaciones, usan otros canales
de circulación, no tienen deseo de
figuración en medios que rentabilicen
lo que crean, detestan el lobby y ser
diplomáticos cuando no están de
acuerdo, y desde su trinchera generan
prácticas artísticas/políticas otras, sin
intermediarios. (Abaplaza, 2016)

Disfrutando de la vitalidad del proceso, compartiendo el tiempo y la vida con los directamente interesados, así mostrar y ofrecer todos los productos realizados, sean gráficos, audiovisuales y también objetuales (útiles) por ahí un elemento importante en toda forma de relacionamiento es el dejar algo más allá del proyecto, no solo la amistad y la fiesta de cierre sino aprehender de una forma de trabajo, de agenciamientos para que los líderes sean estos barriales, juveniles, pastorales empiecen a desarrollar sus propios proyectos desde sus propias necesidades y los produzcan con sus tiempos incorporando a socios estratégicos muy del barrio (la señora de la tienda, el panadero, el de la ferretería), en algunos casos este sistema ha funcionado y hemos visto jóvenes que ya se interesan en plantearse preguntas sobre espacio público, accesibilidad, posicionamientos, problemas socioculturales, gentrificación y cómo realizar su propia producción cultural.

$$
\text { Luego hay cierta problemática }
$$
conceptual que se debe ir trabajando sobre la marcha al mostrar el interés en este tipo de

4 Abaplaza Valenzuela, Rosa, (2014), Arte emergentel arte sumergente, Recuperado el 10 de Febrero del 2016, párr..11, revisión en http://www.arteycritica.org/ensayos/ arte-emergentearte-sumergente/ 


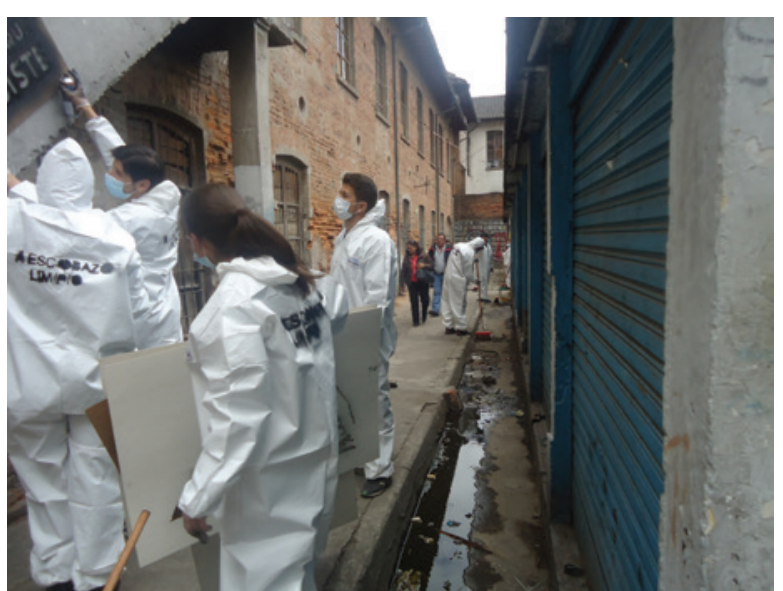

Fig. 7 A escobazo limpio, proyecto realizado por el Colectivo Tranvía Cero, junto con los alumnos de la Escuela de Arquitectura de la Universidad Católica del Ecuador, dentro del marco del X Laboratorio Ciudad de Quito, Mercado de San Roque, (2015), foto propiedad de la memoria de Tranvía Cero

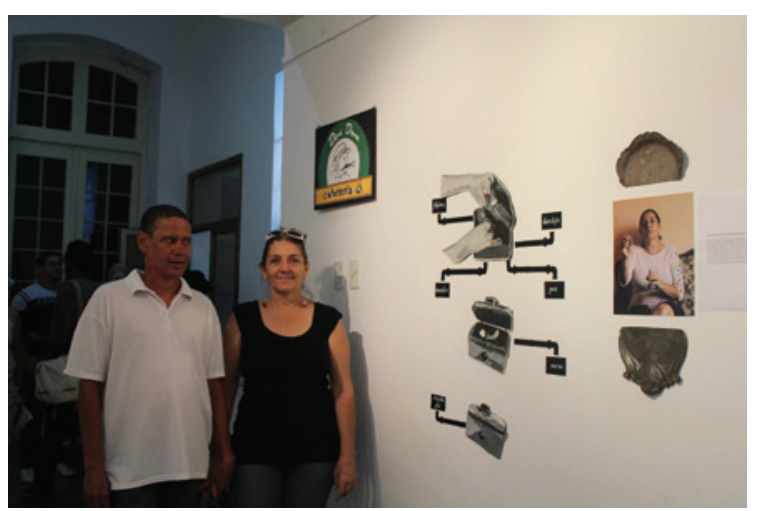

Fig. 8 La Habana Patent, proyecto presentado en la XI Bienal de la Habana, propuesta realizada por el Colectivo Tranvía Cero, 2012, foto propiedad de la memoria de Tranvía Cero.

discusiones, como el interpelar a la propia comunidad sobre su accionar, sus propias formas de organización, las necesidades de cooperar hacia fines colectivos, lo que se debe determinar claramente es que no se trata de trabajo social, nadie está ahí de buena gente o de patriota, se trata del interés que tienen las dos partes en desarrollar un proyecto o cubrir necesidades existentes, el problema es cuando se pone al arte como membrete, como relleno del espectáculo final para tapar varias falencias críticas, ahí es cuando se asemejan ciertos procesos a una estética del amague, de la conveniencia y no cumple ninguna función ni tiene valor alguno, lo único que sirve es para llenar informes, horas libres o como dice Eric Gill, que se "añade como si fuera una salsa para hacer tolerar un manjar rancio y maloliente".

...Cuándo comprenderán los dirigentes revolucionarios que la cultura es un estupefaciente, un opio más adormecedor todavía que la religión?, pues aun cuando fuera cierto que la religión es el opio de los pueblos, es peor envenenarse que envenenar, matarse que matar. ¡Al diablo con la Cultura! Con la cultura en cuanto aditamento. Con la cultura que se añade, como si fuera una salsa, para hacer tolerar un manjar rancio y maloliente (Gill, 1974)..$^{5}$

La Presentación Final varía según las condiciones y las propuestas, A escobazo limpio (gráfico 7), Tranvía Cero actúa desde la irrupción del sitio escogido a intervenir, su presentación se basa en agarrar una escoba y limpiar, las cachinerías, los zaguanes, los resentimientos, pero también crear un diálogo entre las autoridades del Mercado de San Roque, las organizaciones de vendedores, la gente de los locales, los comerciantes para visibilizar las problemáticas que la viven día a día.

\section{En La Habana Patent (gráfico 8)}

Tranvía Cero llega a un consenso para que en la presentación final del proyecto, realizado en la Casa del Alba, dentro del marco de la XI Bienal de la Habana, donde los participantes en el proceso estén presentes junto a su invención, ya que el proyecto trata de ir recuperando esas formas de inventiva popular para la sobrevivencia, importa estar en el sitio, estar presente, ser parte de la creación artística y así ir averiando esa idea caduca de la genialidad del artista y su gran ego.

Che guagua (gráfico 9) identifica a un grupo objetivo de la tercera edad de Quilmes

5 Eric Gill, Al diablo con la cultura, en Herbert Read, (Buenos Aires, Proyección 1974). 


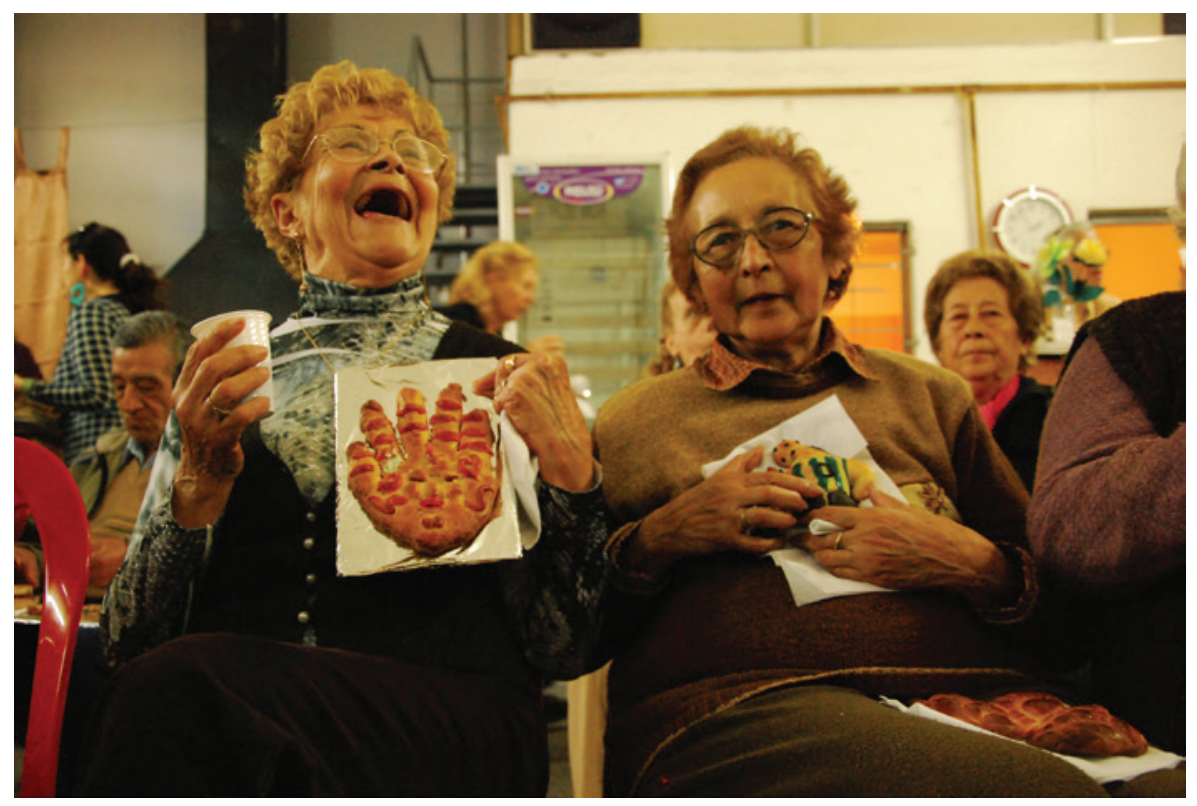

Fig. 9 Che guagua, proyecto presentado en el Festival de Arteenacción en Buenos Aires, Argentina, desarrollado por el Colectivo de arte Tranvía Cero y la Fundación Sapo de Agua (San

Sebastián-Quito) para la Villa Esmeralda, Centro del Adulto Mayor de Quilmes (2010).

(Argentina) con la Fundación Sapo de Agua (Quito) y las pone en diálogo a la distancia, en la presentación final del proyecto se entregan ofrendas (guaguas de pan y colada morada) a los participantes cuya motivación es compartir su memoria histórica, sus vivencias, aspiraciones y tradiciones para guardarlas en un video documental, lo interesante es que ellos también nos envían sus ofrendas al grupo que trabajó los panes en Quito, una especie de tráfico de patrimonios, trueque, intercambio, charlas emotivas por Skype, luego cartas y también encuentros, el generar esos acercamientos, ser ese nexo invisible también es parte del proceso de entablar propuestas interrelacionales.

\section{CONCLUSIONES}

Para concluir quisiera anotar que este tipo de prácticas, también conocidas como outsiders o fuera del arte al abordarlas desde ciertos aspectos sociopolíticos y socioculturales intentan fracturar, averiar el sistema social que se debate en la actualidad, el consumismo, los tiempos acelerados, la desintegración familiar, el progreso, la competencia hacia otras sensibilidades vitales que han ido forjando la humanidad: la solidaridad, el arrimar el hombro, el escuchar al otro, la tolerancia, pero también la visibilización de problemáticas, el diálogo y la discusión comunitaria para exigir espacios y necesidades barriales, o como decía el profesor Eduardo Kingman en una charla acerca del accionar comunitario:

$\ldots$ de hecho el arte tiene unas ventajas que no tiene la antropología, tiene otros lenguajes, otras posibilidades de comunicación y ya que se ha entrado en este tipo de diálogos hay que entrar en una reflexión conceptual de lo que significa el arte contemporáneamente y lo que significa el arte aquí en el Ecuador. Me parece a mí que de modo práctico, proyectos como al zur-ich, han abierto un camino distinto, no sea solo el problema de las galerías 
o no galerías, sino el problema de cómo devolver la politicidad al arte. (Kingman, 2014). ${ }^{6}$

¡A la mierda el espacio público que viva la calle!

Manuel Delgado Ruiz Antropólogo español

\section{Bibliografía}

Echeverría, B., (2010), Definición de la Cultura, México DF: ITACA

Catálogo Las Biblios Creactivas, donde nada es lo que parece y de todo se aprende, (2012), Quito (pág. 17), revisión en https://issuu.com/ makeatuvida/docs/lasbiblioscreactivas

Abaplaza Valenzuela, R.(2014), Arte emergentel arte sumergente, Recuperado el 10 de Febrero del 2016, párr..11, revisión en http://www. arteycritica.org/ensayos/arte-emergenteartesumergente/

Gill, E. (1974), Al diablo con la cultura, en Herbert Read, Buenos Aires, Proyección.

Kingman, E. Conferencia visiones y particularidades del accionar socio-cultural en la lógica comunitaria, en el marco del XIII Encuentro de arte y comunidad al zur-ich 2014, texto tomado del catálogo-memoria anual, p.27, más información sobre el proyecto acudir

www.arteurbanosur.blogspot.com

6 Catálogo del XIII Encuentro de arte y comunidad al zur-ich 2015, conferencia intervención de Eduardo Kingman, p. 27 